\title{
Identification of the Intermodal Vector of Criteria and Correct Training in Mathematical Education: Evaluating an Innovative Potential of an Idea and its Methodical Implementation
}

\author{
Vladimir Selutin ${ }^{1, a *}$, Natalia Yaremko ${ }^{2, b}$, Oksana Krasnova ${ }^{2, c}$ \\ 1 Orel State University, 302026, 95 Komsomolskaya str., Orel, Russia \\ 2 Penza State University, 440026, 40 Krasnaya str., Penza, Russia \\ aselutin_v_d@mail.ru, byaremki@yandex.ru, 'oksana_krasnova@mail.ru \\ ${ }^{*}$ Corresponding author
}

Keywords: criterion, correct, preparation, mathematical education, theory of functioning and development of systems of pedagogical interactions, diagnostic levels, stages, modules

\begin{abstract}
It is shown that the selection of a controlled single circuit of the criterion-correctness in training in the content of education of Bachelors in physical and mathematical areas and its methodological implementation through a six-level mechanism of the theory of functioning and development of systems of pedagogical interactions has innovative characteristics with the potential of widespread adoption. The integration of the educational system solves in its plane the problem of object separation in mathematics education, contributes to the formation of a holistic picture of the world, the realization of the idea of incomplete knowledge. Didactic characteristics of a system: practical and methodological relevance, meaningful value, didactic logic of construction, clarity of installations and diagnostics, performance, optimality, the possibility of creative reproduction, and the possibility of technologizing system monitoring.
\end{abstract}

\section{Introduction}

Correctness is a concept that is relevant in almost all professional fields, including all components of activity with it: knowing the criteria, recognizing correct/incorrect objects, the ability to adequately act in situations of incorrectness, including lack, irrelevance of data, difficulties in isolating essential data and canonical models in real stochastic processes complicated by numerous noises and inclusion in many systems of different nature. In education of mathematicians, correctness is a metacategory. Like other metacategories, it is formed and controlled on the content of various academic subjects, it is refined, the methods of working with it are generalized, and universal skills are achieved as a result [1]. Due to the high professional exploitation of the concept in a variety of particular tasks, it is not possible to reduce training in the field of mathematical correctness to one course. But to isolate this direction as a significant interdisciplinary line and to create a controlled contour of its development is a productive idea.

\section{Methodology}

The idea was didactically implemented on the basis of the apparatus of the theory of the functioning and development of systems of pedagogical interactions (O. V. Krasnov $[2 ; 8]$ ). The context of mathematical correctness in the content of mathematical education (Bachelor's degree in physical and mathematical areas) is highlighted in a single diagnostic form: six levels on the way of forming the criterion-correctness mathematical competence (cognitive, activity, and subject-personal components) have been meaningfully characterized from general everyday concepts to practical knowledge of the theory mathematical correctness and autonomous solution of nontrivial problems in this field. This allowed: 1) to apply a single diagnostic model in the ascertaining and formative experiment with students from different directions; 2 ) to optimize the process as a logical chronology of stages (orientational, adaptive, functionalization, optimization, autonomization), each of which is a transition from the achieved to the next six levels (the sixth level for Bachelors is not fixed). Levels are the key points in the preparation process, statically ("the moment when the student became capable ...": the results and quality gains are "in the student"), the recorded achievements of the system in the process. 


\section{Study}

The goal-setting in the developed concept and methodical system of the criterion-correctness in training in mathematics education is implemented based on educational standards: in the Federal State Education Standard for Undergraduate Students of Physico-Mathematical Directions, the competences are differently associated with operating the concept of correctness, their typology is carried out (key, general subject; relation to personal, regulatory, cognitive, communicative, universal learning activities), the analysis of the composition (knowledge, activity, personal) and the generalized competences in the field of mathematical correctness are formulated: (a) the ability to work with a mathematical problem on the basis of the concept "correctness"; (b) the ability to identify the incorrectness of mathematical objects (a mathematical model, the formulation of problems, evidence, the application of methods, the interpretation of observation results, etc.) and own ways of transforming it into correctness; (c) the ability to build oral and written speech, to lead a scientific discussion, to carry out the thinking process in the correct question-answer form; (d) the ability to analyze philosophical, ideological, natural-scientific, and personally significant problems from the point of view of the concept of "correctness". The developed methodical system of criterion-correctness in training is focused on developing, general cultural, educational, scientific, applied, educational goals.

The training courses, in which the formation of criterion-correctability competence is carried out, are represented by: the program basic component of the mathematical cycle disciplines (higher mathematics, mathematical analysis, algebra, geometry, equations of mathematical physics, numerical methods, history of mathematics and computer science); the variable component (functional analysis, the theory of functions of a complex variable, the history of mathematics and computer science, continuous mathematical models, the mathematical theory of mass service. The stages of the process [3-6] are implemented, in addition to the basic and variable parts of the content of education, through eight interdisciplinary modules. (1. The concept of mathematical correctness. 2. Correctness of a mathematical task. 3. Correctness of formulating a mathematical task. 4. Correctness of a mathematical model. 5 Correctness of the definition concepts. 6 . The correctness of the question and answer. 7. Correctness of the proof, applying the method, presenting the material, interpreting results of observations, computational algorithms. 8. Correctness of formulating the Cauchy problem for ordinary differential equations. The concept of setting boundary and inverse problems). Also, the stages are implemented in two special courses (Correct and incorrect problems of mathematical physics. Correctness of definitions and a regular generalization of mathematical concepts). The content of the system is not a mechanical connection of several mathematical objects or disciplines, but it is a product of interdisciplinary synthesis.

In the methodological implementation of the interdisciplinary vector of forming competence in the field of mathematical correctness, the means, methods, and principles are: 1. Use of correct and incorrect tasks in educational content. 2. Solving problems in which the properties of ill-posed problems manifest themselves: the activity to solve them goes through all stages, has a spiral shape; system properties of the task include interactions between the components of each task with each other and with the external environment, changing the correctness with variation; potential (existing in the future) and real (presently existing) possibilities of "overcoming incorrectness"; overcoming of incorrectness by variation of the subject area (narrowing or expansion), transition to a new subject area, to a generalization of concepts, to a correct system of subtasks, to approximations. 3. The use of natural science problems, the compilation of their mathematical model and the study of its correctness. 4. Illustration of the correctness of the methods and their application in the study and processing of the results of observations. 5. Inclusion of counterexamples, sophisms, puzzles and their resolution based on the analysis of the correctness of their formulation, the application of methods, justifications, reasoning in the content of mathematical paradoxes. 6. Mastering universal educational actions of cognitive and evaluative nature, corresponding to the concept of "correctness": justification of unambiguous certainty, variation, adjustment. Mastering the methods of "eliminating incorrectness." 7. Organization of dialogues, discussions, question-answer forms of communication in the form of a sequence of correct questions and answers. 8. Formation of students' interrogative type of thinking based on the sequence of correct questions and answers. 9. The solution of problems from the real life of students on the basis of the commonly used meaning of the concept of "correctness." 10. Formation based on the requirements of the correctness of skills to work with information, to carry out its search, to present data in various forms. 11. Formation of a holistic picture of the world, illustration of the idea of incomplete knowledge, the implementation of scientific and educational 
knowledge based on the philosophical meaning of the concept of "correctness."

As a result of the pedagogical experiment, we obtained a justification of how effective the developed methodological system was. The pedagogical experiment showed the feasibility of introducing a methodological system of criterion-correct mathematical training at a university. It has been established that the system of interdisciplinary modules leads the formation of necessary competences to the manipulative (III) level; the special courses "Correctness of definitions and regular generalization of mathematical concepts"and "Correct and incorrect problems of mathematical physics" bring the formation of the criterion-correctness competence to the pragmatic and optimal (IV, V) levels. That is, the experimental work allowed to clarify the content of the process at the stages. In this article, there is no possibility to describe the whole process (stages). We show here in an abbreviated form the contents of several (II-V) levels according to the two qualitative characteristics (Table 1).

TABLE 1. LEVELS IN THE PROCESS OF PURPOSEFUL FORMATION OF COMPETENCE IN THE FIELD OF MATHEMATICAL CORRECTNESS IN THE INTERDISCIPLINARY METHODICAL SYSTEM.

\begin{tabular}{|c|c|c|}
\hline \multirow{2}{*}{ Level } & \multicolumn{2}{|c|}{ Qualitative level characteristics } \\
\hline & Cognitive component & Activity \\
\hline 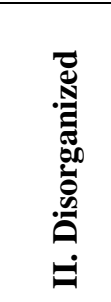 & $\begin{array}{l}\text { knowledge-recognition: } \\
- \text { primary ideas about mathematical } \\
\text { correctness in common and terminological } \\
\text { terms, } \\
- \text { familiarity with the principle of } \\
\text { incompleteness of knowledge based on } \\
\text { mathematical correctness }\end{array}$ & $\begin{array}{l}\text { attempts of orientation, understanding: } \\
\text { - delineation of common and terminological } \\
\text { concepts of mathematical correctness; } \\
\text { - initial acquaintance with the composition of } \\
\text { activities to identify incorrectness by the } \\
\text { unequivocal definiteness of single } \\
\text { mathematical objects, by their variation. }\end{array}$ \\
\hline 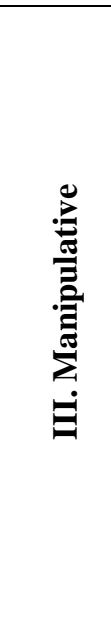 & $\begin{array}{l}\text { copy knowledge: } \\
\text { - terminological correctness of the } \\
\text { mathematical problem according to } \\
\text { Hadamard, Tikhonov, etc.; correctness of } \\
\text { definitions of various concepts, rules of } \\
\text { inference, software, questions and answers; } \\
\text { - ideas about common correctness, } \\
\text { including those of the proof, method, } \\
\text { presentation of materials, formulation of the } \\
\text { problem; } \\
\text { - statement of basic correct and incorrect } \\
\text { tasks, requirements of correctness for } \\
\text { interactive speech, for methods, proof, } \\
\text { formulations. }\end{array}$ & $\begin{array}{l}\text { detailed actions on the model, insufficient } \\
\text { development of actions: } \\
\text { - students list three requirements for } \\
\text { correctness, know the definitions of } \\
\text { conditionally correct problems, reproduce the } \\
\text { solution of incorrect problems, can prove the } \\
\text { stability of the computational algorithm in } \\
\text { standard, usual cases, substantiate the proof } \\
\text { correctness, presentation of the material, } \\
\text { questions and answers according to the existing } \\
\text { sample; } \\
\text { - students have an activity structure and } \\
\text { mechanisms on the justification of unique } \\
\text { definiteness of mathematical objects, on their } \\
\text { variation. }\end{array}$ \\
\hline 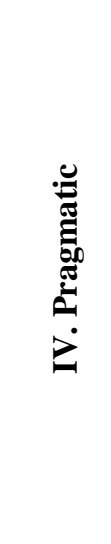 & $\begin{array}{l}\text { knowledge-skills: } \\
\text { - methods of substantiation of correctness } \\
\text { on the basis of an indicative basis of action, } \\
\text { activity "externally"; } \\
\text { - research methods and solutions of model } \\
\text { ill-posed problems, methods of the theory of } \\
\text { problems in standard situations, methods for } \\
\text { substantiating nominal mathematical } \\
\text { correctness in standard cases; } \\
\text { - substantiation of the proof correctness, } \\
\text { method, problem formulation, presentation } \\
\text { of the material - the commonly used } \\
\text { mathematical correctness. }\end{array}$ & $\begin{array}{l}\text { mastered actions: } \\
\text { - conscious recognition and solution of typical } \\
\text { problems and their combinations, conscious } \\
\text { and informed choice of methods for studying } \\
\text { mathematical objects for correctness; } \\
\text { - recognition and solution of typical ill-posed } \\
\text { problems and their combinations, a consciously } \\
\text { informed choice of methods, mechanisms for } \\
\text { studying mathematical objects for correctness, } \\
\text { possession of the methods of the theory of ill- } \\
\text { posed problems and their individual } \\
\text { applications. }\end{array}$ \\
\hline
\end{tabular}




\begin{tabular}{|l|l|l|}
\hline $\begin{array}{l}\text { knowledge-skills, methods of cooperation: } \\
- \text { methods of the theory of ill-posed } \\
\text { problems, the application of the } \\
\text { methodology of this theory when working }\end{array}$ & $\begin{array}{l}\text { - the experience of joint (with a teacher) } \\
\text { educational and cognitive activities with } \\
\text { elements of research in the process of solving } \\
\text { ill-posed tasks, generalizing concepts, when } \\
\text { analyzing the correctness of evidence, } \\
\text { with any task, possession of terminological } \\
\text { correctness at the level of application in } \\
\text { metandard conditions; } \\
- \text { application of the basics of common } \\
\text { mathematical correctness in practical quasi- } \\
\text { professional activities. }\end{array}$ & $\begin{array}{l}\text {-the operational structure of activities on the } \\
\text { substantiation of mathematical correctness, } \\
\text { including those "in the internal plan"; the } \\
\text { application of knowledge and skills for } \\
\text { practical research purposes have been firmly } \\
\text { understood and realized. }\end{array}$ \\
\hline
\end{tabular}

In the formative experiment, statistically significant differences (Fig. 1) between the experimental and control groups were obtained.

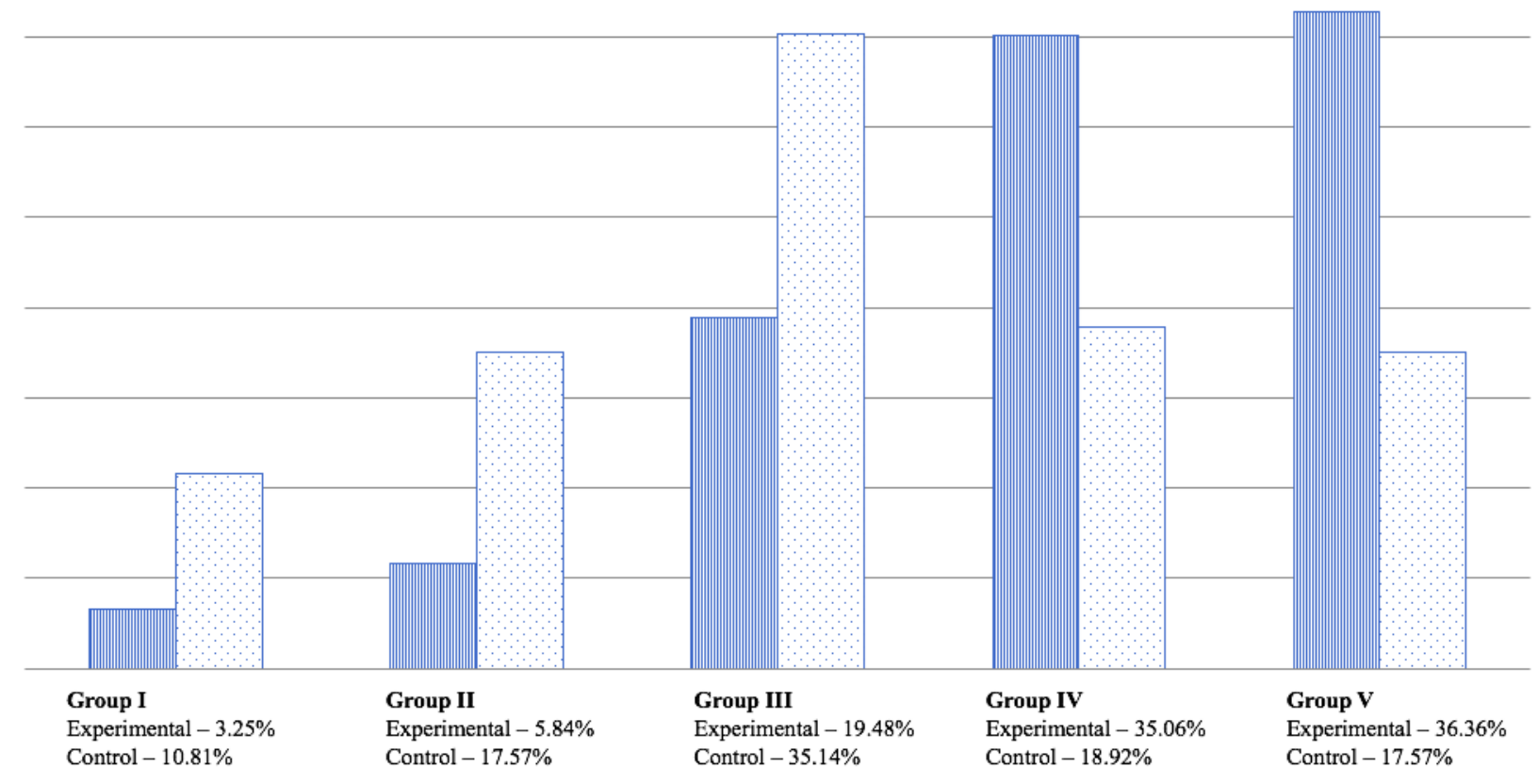

Fig. 1. Distribution of results in groups by levels at the end of the formative experiment (154 and 148 students in the experimental and control groups, respectively, $\chi_{э к с}^{2}=39,04 \geq_{\chi_{0,05}^{2}}=9,49$.)

\section{Conclusion}

The proposed idea of an interdisciplinary managed system of forming competence in the field of mathematical correctness of Bachelors of physical and mathematical areas, the concept developed on its basis and its methodical implementation proved to be successful: the system is functional, in addition to subject and special competencies, the significant result of its application is general intellectual development and changes in the world picture of students. The productive properties of mental cognitive processes are formed; new forms of thinking, attention, memory, perception, and speech acquire new qualities. Correct and incorrect tasks, models, methods, questions and answers serve as educational material, in the activities with which the personality creativity, speech, cognitive processes, and interrogative type of thinking are formed. The concept of "correctness" illustrates the philosophical ideas of gradualism and unlimited knowledge, specifying the idea of incomplete knowledge. The philosophical thesis about the spiral development of concepts is confirmed by many examples through "overcoming incorrectness". Educational and cognitive activity of students goes through all stages, from goal-setting to the analysis of results and transfer to new conditions. 
For students enrolled in the physical and mathematical direction of training, correct and incorrect tasks, models, methods act as a mathematical tool for studying natural science processes. For student studying Computer Science, incorrect and inverse problems are of scientific and professional interest in terms of developing robust algorithms, for example, for inverse problems; the concept of system sustainability is used in the study of economic issues related to the description of markets, demand and consumption, inflation processes and exchange rates.

The integration of the system into the educational process solves in its plane the problem of subject scatteredness in mathematics education.

The obvious practical and methodological relevance of the system, meaningful value, didactic logic of construction, clarity of installations, and diagnostics determine its high competitiveness in the market of educational products and highly appreciated by specialists. From the point of view of the life cycle of pedagogical innovations, these characteristics create conditions for the implementation of all stages of the life cycle of innovation, including the perception, acceptance, assimilation, and application of ideas. The tested approach satisfies all the criteria for viable pedagogical innovation: relevance, effectiveness, optimality, the possibility of creative reproduction, the possibility of technologizing system monitoring [7]. Therefore, it has a high potential for widespread adoption.

\section{References}

[1] Yaremko, N. N. (2012). Mathematical correctness as a meta-concept and as a didactic principle. Artemovsky readings: materials of the VIII All-Russian. scientific-practical conf. from Intern. participation (May 17-18, 2012) (Vol. 1, pp. 75-78). Penza, Russia: PSPU.

[2] Yaremko, N. N. (2013). Pedagogical Education in Russia, 2, pp. 179-187

[3] Yaremko, N.N. (2015). Uchenye zapiski Oryol State University. Ser. Natural, Technical and Medical Sciences, 4(67), pp. 82-86.

[4] N. N. Yaremko, (2013). The system of interdisciplinary integrated modules as a means of implementing the criterion-correctness in mathematical training of university students. In V. V. Orlova (Ed.), Problems of the theory and practice of teaching mathematics: Sat. scientific tr. International scientific conf. "66th Herzen readings" (pp. 90-96). SPb., Russia: RGPU them. A.I. Herzen.

[5] Yaremko, N. N. (2015). Theoretical and methodological foundations of the criterion-correct mathematical preparation of Bachelors of physical and mathematical directions. Orel, Russia: Publishing House of the OSU State Educational Institution of Higher Professional Education.

[6] Gavrilova, M. A., Yaremko, N. N., \& Dmitriyev, D. V. (2015). European Journal of Research and Reflection in Educational Sciences, 3, 1, pp. 56-62.

[7] Shikhnabieva, T., \& Beshenkov, S. (2016). Intelligent system of training and control of knowledge, based on adaptive semantic models. In Smart Education and e-Learning 2016 (pp. 595-603). Berlin, Germany: Springer International Publishing.

[8] Yaremko, N. N., Krasnova, O. V., \& Vlazneva, S. A. (2014). The Criterion-correctness mathematician competence formation on the base of theory of pedagogical interaction systems functioning and development of science and education. Materials of the $V$ International Research and Practice Conference (pp. 153-157). Munich, Germany. 